\title{
Esophageal Endosonography for the Diagnosis of Intrapulmonary Tumors: A Systematic Review and Meta-Analysis
}

\author{
Daniël A. Korevaar ${ }^{a}$ Sara Colellab René Spijker ${ }^{c, d}$ Patrick M. Bossuyt ${ }^{a}$ \\ Lars Konge $^{e}$ Paul Frost Clementsen ${ }^{e, f}$ Jouke T. Annema ${ }^{g}$ \\ ${ }^{a}$ Department of Clinical Epidemiology, Biostatistics and Bioinformatics, Academic Medical Center, University of \\ Amsterdam, Amsterdam, The Netherlands; ' Department of Respiratory Medicine, "C. e G. Mazzoni" Hospital, \\ Ascoli Piceno, Italy; ' Medical Library, Academic Medical Center, University of Amsterdam, Amsterdam, and \\ ${ }^{d}$ Cochrane Netherlands, Julius Center for Health Sciences and Primary Care, University Medical Center Utrecht, \\ Utrecht, The Netherlands; ${ }^{\text {CC}}$ Copenhagen Academy for Medical Education and Simulation (CAMES), Rigshospitalet, \\ University of Copenhagen and the Capital Region of Denmark, Copenhagen, and f Department of Internal Medicine, \\ Zealand University Hospital, Roskilde, Denmark; ${ }^{9}$ Department of Respiratory Medicine, Academic Medical Center, \\ University of Amsterdam, Amsterdam, The Netherlands
}

\section{Keywords}

Esophageal ultrasound - Diagnosis · Lung cancer diagnosis · Clinical epidemiology

\begin{abstract}
Background: Biopsy-based diagnosis in patients with paraesophageal intrapulmonary tumors suspected of lung cancer is crucial for adequate treatment planning. Objective: To evaluate the performance of transesophageal endoscopic ultrasound-guided fine-needle aspiration (EUS-FNA) in the diagnosis of intrapulmonary tumors located near or adjacent to the esophagus. Methods: We performed a systematic review (PROSPERO, CRD42016033737) and searched MEDLINE, Embase, BIOSIS Previews, and Web of Science on September 22, 2016, without date or language restrictions. We included studies that evaluated the yield and/or sensitivity of EUS-FNA for diagnosing intrapulmonary tumors. Yield was defined as the number of patients in whom EUS-FNA made a biopsy-proven diagnosis (malignant or nonmalig-
\end{abstract}

nant) relative to the total number of patients on whom EUSFNA was performed. Sensitivity was defined as the number of patients in whom EUS-FNA made a biopsy-proven diagnosis of malignancy relative to the total number of patients in whom the tumor was found to be malignant. We performed a random-effects meta-analysis. Results: Of 3,320 search results, 11 studies were included. Ten had a high risk of bias. The total number of patients was 313; the proportion of patients with malignancy ranged from 87 to $100 \%$ across these studies. The average yield was 0.90 (95\% Cl 0.82-0.95) and the average sensitivity was $0.92(0.83-0.96)$. In the subgroup of prospective studies $(n=3)$, the average yield was $0.80(0.56-0.93)$ and the average sensitivity was $0.83(0.58-$ 0.95). EUS-FNA-induced complications were reported for $5 / 256$ patients $(2.0 \%)$ for whom this information was available. Conclusions: Although the number of high-quality studies is limited, these findings suggest that EUS-FNA is safe and has a high yield for diagnosing intrapulmonary tumors.

(c) 2016 The Author(s)

Published by S. Karger AG, Basel

\begin{tabular}{ll}
\hline KARGER & $\begin{array}{l}\text { ( ) 2016 The Author(s) } \\
\text { Published by S. Karger AG, Basel }\end{array}$ \\
E-Mail karger@karger.com & Karger \\
www.karger.com/res & $\begin{array}{l}\text { This article is licensed under the Creative Commons Attribution- } \\
\text { NonCommercial-NoDerivatives 4.0 International License (CC BY- } \\
\text { NC-ND) (http://www.karger.com/Services/OpenAccessLicense). } \\
\text { Usage and distribution for commercial purposes as well as any dis- } \\
\text { tribution of modified material requires written permission. }\end{array}$
\end{tabular}

Daniël A. Korevaar, MD, PhD

Department of Clinical Epidemiology, Biostatistics and Bioinformatics Academic Medical Center, University of Amsterdam, Meibergdreef 9 NL-1105 AZ Amsterdam (The Netherlands) E-Mail d.a.korevaar@amc.uva.nl tribution of modified material requires written permission. 


\section{Introduction}

Lung cancer is the number one cause of cancer-related mortality in the world [1]. Accurate biopsy-based diagnosis of intrapulmonary tumors in patients suspected of lung cancer is crucial for adequate planning of treatment. In patients with centrally located lesions, clinical guidelines recommend conventional flexible bronchoscopy to obtain a tissue diagnosis [2]. However, this technique is not feasible or nondiagnostic in a substantial proportion of patients, especially in the absence of endobronchial abnormalities [2]. Other, more recently established options involve linear endobronchial ultrasound with real-time guided transbronchial needle aspiration (EBUS-TBNA) for intrapulmonary tumors located in close proximity to the major airways $[3,4]$, and navigational bronchoscopy or radial EBUS-TBNA for peripherally located tumors [5, 6]. However, each of these techniques requires the tumor to be located near an airway, which is not always the case. In those cases, computed tomography (CT)-guided transthoracic needle aspiration is sometimes used, but it is unattractive because of a substantial risk of pneumothorax and hemoptysis [7].

In patients in whom CT imaging shows that the intrapulmonary tumor is located near or adjacent to the esophagus, transesophageal endoscopic ultrasound-guided fine-needle aspiration (EUS-FNA) may provide a valuable minimally invasive alternative (see Fig. 1 and case example in Box 1) [8-10]. The role of EUS-FNA in mediastinal nodal staging in patients with proven or suspected lung cancer is well established and part of the current clinical guidelines [11-15]. However, its performance in obtaining an adequate tissue sample directly from intrapulmonary tumors has received much less attention $[8,10]$.

EUS-FNA is a safe and inexpensive procedure, especially if the alternative for obtaining a tissue diagnosis is surgery. Therefore, if sufficiently feasible, it is likely to be a useful test in the diagnosis of intrapulmonary tumors, not only after a nondiagnostic bronchoscopy but also as the first invasive test to be applied in the diagnostic workup of patients with suspected lung cancer. A major advantage would be that biopsies from the intrapulmonary tumor, and biopsies for staging purposes from the mediastinum or other areas, can be taken in a single session [9].

The yield and sensitivity of EUS-FNA for diagnosing intrapulmonary tumors located near or adjacent to the esophagus are not well established [8], and they can be negatively impacted during different steps of the procedure: the tumor may not be visualized by EUS; if visualized, it may not be possible to take a biopsy; and if biop-

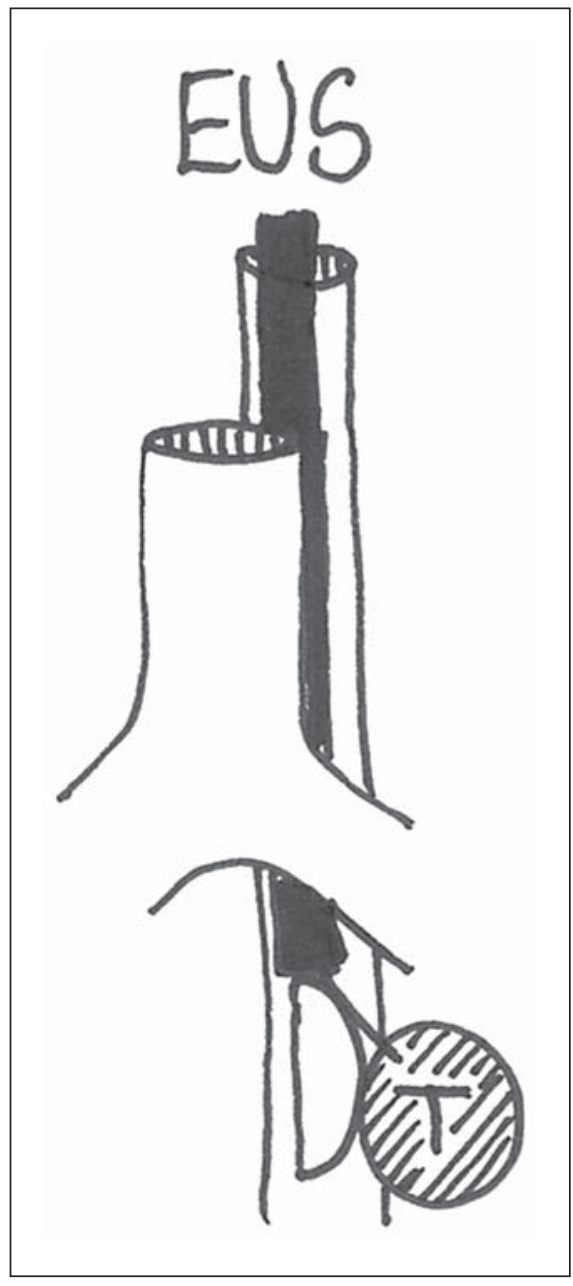

Fig. 1. Intrapulmonary tumors $(\mathrm{T})$ that cannot be reached from the major airways may be biopsied from the esophagus. EUS, endoscopic ultrasound.

sied, the material may not be representative. In each of these cases, EUS-FNA can be considered as nondiagnostic, and additional testing would be needed to establish a tissue diagnosis.

We performed a systematic review and meta-analysis to obtain summary estimates of the yield and sensitivity of EUS-FNA for diagnosing intrapulmonary tumors located near or adjacent to the esophagus in patients with suspected lung cancer.

\section{Material and Methods}

The protocol of this systematic review was prospectively registered at PROSPERO under registration No. CRD42016033737. 


\section{Eligibility Criteria}

Studies were included if they evaluated the yield and/or sensitivity of EUS-FNA for diagnosing intrapulmonary tumors located near or adjacent to the esophagus in patients with suspected lung cancer, where the aim was to obtain a tissue sample from the intrapulmonary tumor. Studies were eligible regardless of whether they selected patients based on the results of previous tests or based on tumor size. Both prospective and retrospective studies were eligible.

We also included studies if they aimed to obtain a tissue diagnosis from intrapulmonary tumors invading the mediastinum or central vessels, but we excluded studies that focused on diagnosing mediastinal tumors, as well as studies that aimed to diagnose an intrapulmonary tumor by sampling metastases in, for example, the mediastinum, liver, or adrenal gland.

We also excluded studies that focused on T-, N-, or M-staging rather than on diagnosing intrapulmonary tumors, studies that focused on EBUS-TBNA instead of EUS-FNA, studies using radial instead of linear EUS equipment, and studies that aimed to sample an intrapulmonary tumor in fewer than 10 patients.

\section{Search and Selection}

The literature searches on MEDLINE, Embase, BIOSIS Previews, and Web of Science were developed by a medical information specialist (R.S.). The complete search strategy is provided in online supplementary material A (for all online suppl. material, see www.karger.com/doi/10.1159/000452958). No date or language restrictions were applied. The final searches were performed on September 22, 2016.

The titles and abstracts of the search results were examined by 2 independent investigators (D.A.K. and S.C.). If an article was considered potentially eligible by one of them, they independently assessed the corresponding full article for inclusion, with disagreements being resolved by discussion. If necessary, a third investigator (J.T.A.) made the final decision.

To identify additional relevant publications, 1 investigator (D.A.K.) screened the reference lists of the included articles, and all articles citing them (through Google Scholar). To identify unpublished studies, this investigator also screened ClinicalTrials. gov and the WHO International Clinical Trials Registry Platform Search Portal, without time limits. These additional searches were performed on March 24, 2016.

\section{Data Extraction}

One investigator (D.A.K.) extracted data from all the included studies; data extraction was verified by a second investigator (S.C.). We extracted the first author, year of publication, journal, and country of patient recruitment. We also recorded whether or not patients had undergone previous (nondiagnostic) tests to obtain a tissue sample of the intrapulmonary tumor, and whether or not there were any restrictions with regard to the location or size of the tumor in the inclusion criteria. We then extracted details about age and gender, the type of test under evaluation (EUS with an endoscope vs. EUS-B with an EBUS-scope), the experience of the endoscopist(s), the availability of rapid on-site cytological evaluation, the needle type, the number of needle passes performed, procedure length, tumor size, the reference standard, and any complications from EUS-FNA.

We also extracted the total number of patients on whom EUSFNA was performed with the aim of diagnosing an intrapulmo-

\section{Case example: \\ A 66-year-old smoker presented with a centrally located intrapulmonary tumor in the left upper lobe on a CT scan (Image A). Conventional bronchoscopy and EBUS-TBNA were nondiagnostic. CT-guided transthoracic needle aspiration only showed necrotic tissue (Image B). During EUS, the tumor was clearly visualized, and FNA was performed, which showed squamous cell carcinoma (Image C). EUS-FNA, endoscopic ultrasound-guided fine- needle aspiration; CT, computed tomography; EBUS-TBNA, endobronchial ultrasound with real-time guided transbronchial needle aspiration.}

Image A:

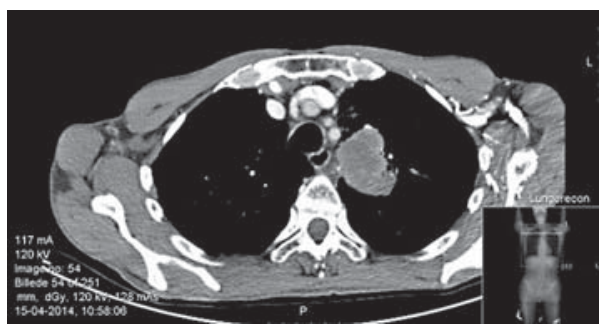

Image B:

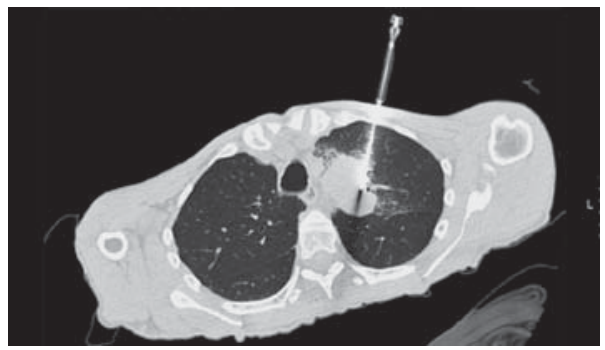

Image C:

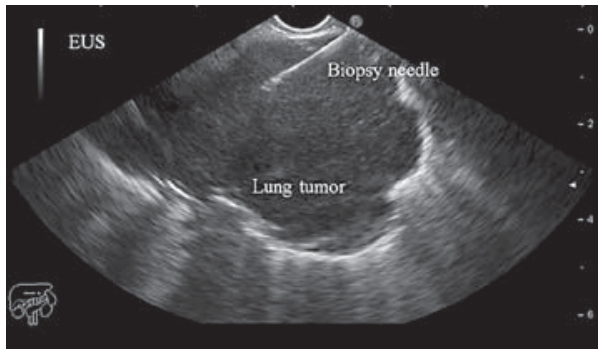

Box 1. EUS-FNA for diagnosing intrapulmonary tumors after a nondiagnostic bronchoscopy

nary tumor, the number of patients in whom the tumor could be visualized by EUS, the number of patients from whom an adequate tissue sample could be obtained by EUS-FNA, the number of patients in whom EUS-FNA made a correct biopsy-proven diagnosis (malignant or nonmalignant), the number of patients in whom EUS-FNA diagnosed a malignancy, and the number of patients in whom the targeted intrapulmonary tumor turned out to be malignant, as determined by the reference standard. 


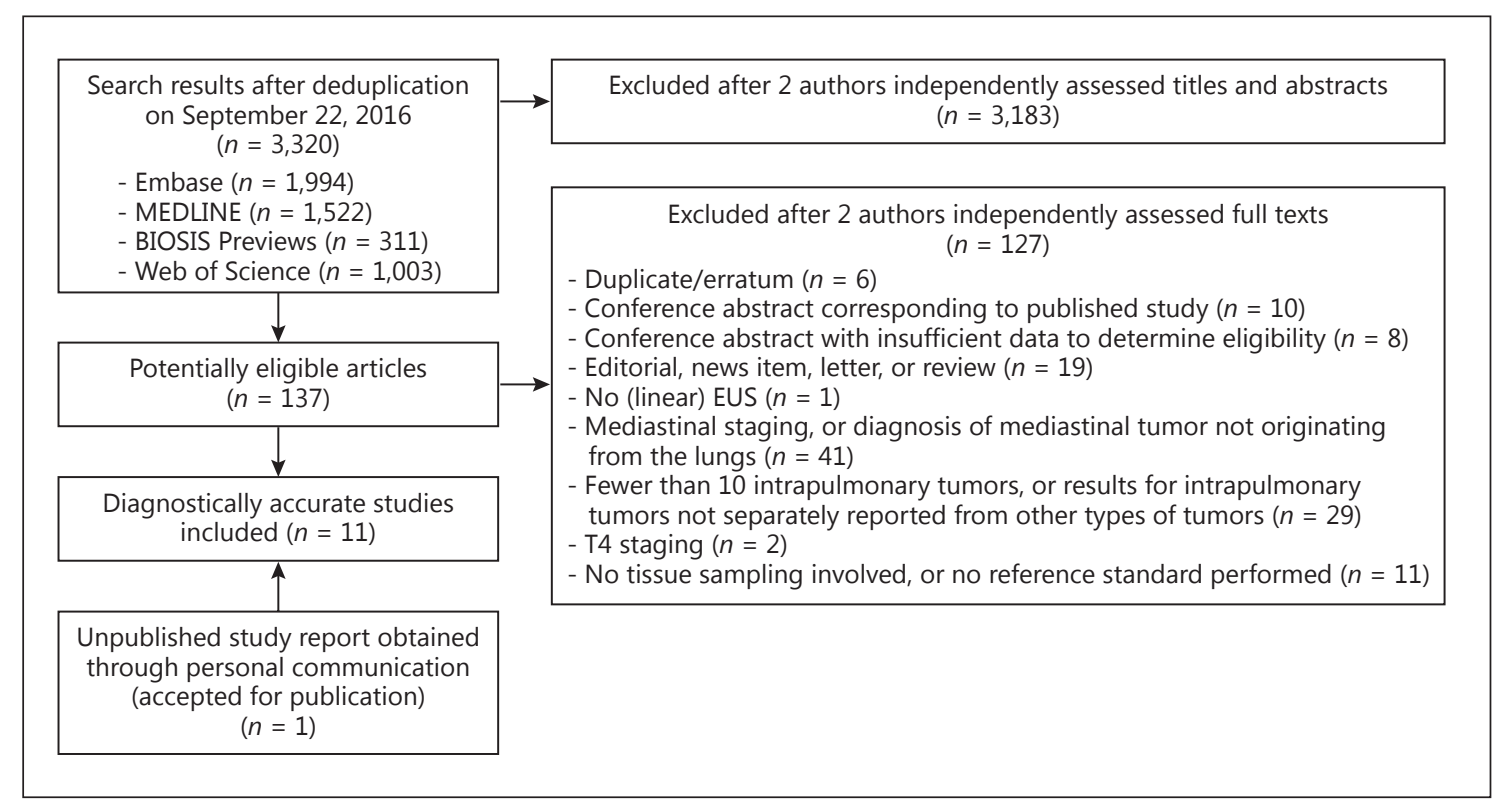

Fig. 2. Selection of studies.

We considered EUS-FNA to have made an incorrect diagnosis if a subsequently performed reference standard resulted in a different diagnosis, or if EUS-FNA was nondiagnostic so that further invasive procedures were needed to arrive at a diagnosis. We considered EUS-FNA to have made a correct diagnosis of malignancy if the tissue material contained malignant cells. We did so because a reference standard is rarely performed in such cases and falsepositive EUS-FNA findings are known to be rare.

\section{Quality Assessment}

Two reviewers (D.A.K. and S.C.) independently assessed the risk of bias in each of the studies included, using the QUADAS-2 tool [16]; here, as well, disagreements were resolved by consensus. If necessary, a third investigator (P.M.B.) made the final decision.

Study design features associated with a high risk of bias were: (1) retrospective (nonconsecutive) inclusion of patients; (2) exclusion of patients in whom the intrapulmonary tumor could not be visualized by EUS; (3) a case-control design; (4) endoscopists that were not blinded to the final diagnosis of the intrapulmonary tumor while performing the procedure; (5) a suboptimal reference standard for patients with a nondiagnostic or nonmalignant EUSFNA (e.g., clinical follow-up); (6) partial verification of included patients with a nondiagnostic or nonmalignant EUS-FNA, meaning that some of these patients did not receive a reference standard; (7) differential verification of patients with a nondiagnostic or nonmalignant EUS-FNA, meaning that some patients received an optimal reference standard, but others received a suboptimal reference standard; and (8) exclusion of patients with missing reference standard results.

The QUADAS-2 tool can also be used to analyze concerns about applicability, but these were not taken into account, as such concerns were avoided by narrowing our inclusion criteria - for example, by excluding studies that used radial instead of linear EUS equipment.

Esophageal Endosonography for Intrapulmonary Tumors

\section{Primary Outcomes}

The primary outcome measures in this review were: (1) the yield of EUS-FNA for diagnosing intrapulmonary tumors and (2) the sensitivity of EUS-FNA for diagnosing malignant intrapulmonary tumors.

Yield was defined as the number of patients in whom EUS-FNA made a correct biopsy-proven diagnosis (nonmalignant or malignant) relative to the total number of patients on whom EUS was performed with the aim of diagnosing an intrapulmonary tumor.

Sensitivity was defined as the number of patients in whom EUS-FNA made a correct biopsy-proven diagnosis of any malignancy relative to the total number of patients in whom the targeted intrapulmonary tumor turned out to be malignant.

\section{Analysis}

For each included study, we calculated estimates of yield and sensitivity, together with 95\% CIs, using the normal approximation. We then performed a univariate random-effects meta-analysis according to DerSimonian-Laird where proportions were logit transformed [17] to produce summary estimates of yield and sensitivity.

We calculated $I^{2}$ statistics to assess the extent of heterogeneity; an $I^{2}$ statistic $>50 \%$ is a rough indicator of substantial heterogeneity [18]. Sources of heterogeneity were taken into account by performing subgroup analyses if at least 3 studies per subgroup were available. We focused on 2 potential methodological sources of heterogeneity that are likely to be associated with a major risk of bias: (1) the type of study (retrospective vs. prospective) and (2) explicitness in reporting of the total number of patients in whom the tumor could be visualized by EUS (not reported or unclear vs. explicitly reported). The latter subgroup analysis was performed because it was unclear for several studies whether patients in whom the tumor could not be visualized by EUS were excluded from the analysis. Excluding such patients leads to overestimation of test performance. 


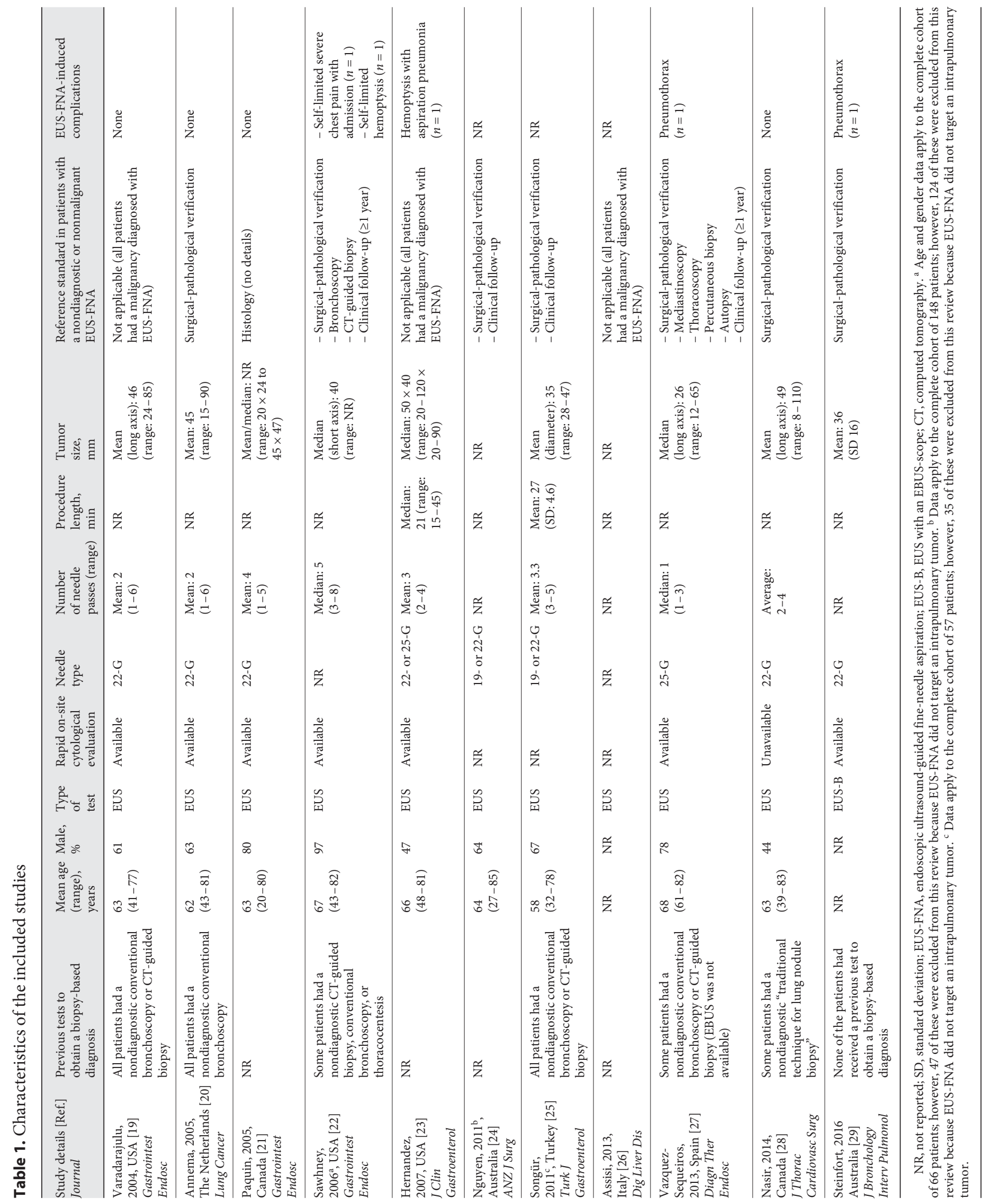


Four potential clinical sources of heterogeneity were defined: (1) previous tests had been performed to obtain a tissue sample of the intrapulmonary tumor and they were nondiagnostic (yes vs. no); (2) the size of the intrapulmonary tumor (as reported in the included studies); (3) the type of scope used (EUS vs. EUS-B); and (4) the availability of rapid on-site cytological evaluation (yes vs. no).

Data analysis was performed using the "meta" package in R version 3.0.

\section{Results}

\section{Study Selection}

The electronic searches yielded 3,320 search results, from which 10 studies were included [19-28]. Two of these included studies were conference abstracts $[21,26]$. Through personal communication, we were also able to include 1 additional study for which the report had been accepted for publication at the time of our searches but which had not yet been published [29]. Figure 2 provides the details of the study selection process, with reasons for excluding studies. Screening reference lists, citing articles, and trial registries did not reveal any additional relevant studies.

\section{Study Characteristics}

The detailed characteristics of the 11 studies included are reported in Table 1 . These studies were published over a 12-year period - the first in 2004 and the last in 2016. In 3 studies, all the included patients had undergone a previous nondiagnostic test such as conventional bronchoscopy to obtain a tissue sample of the intrapulmonary tumor, while in 3 other studies, only some patients had had a previous nondiagnostic test, and in 1 study, none of the patients had undergone previous testing to obtain a biopsy-based diagnosis. Information about previous testing was not reported in the remaining 4 studies. For most studies, it was unclear whether there were any restrictions with regard to the location or size of the tumor (Table 2).

The mean or median age of the patients ranged from 58 to 68 years, and the ratio of male patients ranged from 44 to $97 \%$. The type of test was EUS in 10 studies and EUS-B in 1 study. None of the studies reported on the experience of the endoscopist. Rapid on-site cytological evaluation was available in 7 studies, unavailable in 1 study, and not reported in 3 studies.

Most studies $(n=8)$ used a $22-\mathrm{G}$ needle. The mean or median number of needle passes ranged from 1 to 5 in the 7 studies that reported this information. The median length of the procedure was $21 \mathrm{~min}$ in one study, with a mean length of $27 \mathrm{~min}$ in another study; this information
Table 2. Definitions of targeted intrapulmonary tumors

\begin{tabular}{ll}
\hline $\begin{array}{l}\text { Study [Ref.], } \\
\text { year }\end{array}$ & $\begin{array}{l}\text { Targeted intrapulmonary tumors were defined } \\
\text { as... }\end{array}$ \\
\hline $\begin{array}{l}\text { Varadarajulu } \\
\text { [19], 2004 }\end{array}$ & $\begin{array}{l}\text { "lung mass [adjacent to or abutting the } \\
\text { esophagus] that was either confined to the lung } \\
\text { parenchyma or was invading the mediastinum" }\end{array}$ \\
\hline $\begin{array}{l}\text { Annema [20], } \\
\text { "[intrapulmonary] tumor located near }(<1 \mathrm{~cm}) \\
\text { or adjacent to the esophagus" }\end{array}$ \\
$\begin{array}{ll}\text { Paquin [21], } & \text { "lung masses accessible through the esophagus" }\end{array}$ \\
\hline
\end{tabular}

Sawhney [22], "primary lung tumors that abutted or invaded 2006 the mediastinum"

Hernandez [23], "masses that resided within the lung 2007 parenchyma and were adjacent to or abutting the esophagus"

Nguyen [24], "lung lesions"

2011

Songür [25], "pulmonary masses invading the mediastinum" 2011

Assisi [26], 2013 "pulmonary localization of disease"; "localized in dorsal superior segments"

Vazquez- "lung masses [...] with the closest margin

Sequeiros [27], believed to be in sufficient proximity to the 2013 esophageal wall"; "lung masses were located in the vicinity of the cervical/upper esophagus ( $n=19$; each $<1 \mathrm{~cm}$ from esophagus) or mid esophagus ( $n=43$; each $<2 \mathrm{~cm}$ from the esophagus)"

Nasir [28], 2014 "lung mass suspicious for either a primary or secondary neoplasm of the lung"; "mean distance between lesion and esophagus: $25 \mathrm{~mm}$ (range 0-46)"

Steinfort [29], "pulmonary parenchymal lesions [...] adjacent 2016 to the esophagus on Computed Tomography of the chest"

was not reported in the remaining 9 studies. The mean or median long axis of the targeted tumor ranged from 26 to $50 \mathrm{~mm}$.

\section{Study Quality}

Detailed results of the quality assessment of the studies included are provided in online supplementary material B. All but 1 study had at least 1 item with a high risk of bias. The most common source of bias was retrospective inclusion of patients, which was the case in 8 studies. In 6 studies, it was unclear whether they excluded patients 
Table 3. Yield and sensitivity of EUS-FNA for diagnosing intrapulmonary tumors located near or adjacent to the esophagus

\begin{tabular}{|c|c|c|c|c|c|c|c|c|c|}
\hline Study [Ref.], year & Type of study & $\begin{array}{l}\text { Total EUS } \\
\text { performed, } \\
n\end{array}$ & $\begin{array}{l}\text { Total with any } \\
\text { malignancy, } \\
n(\%)\end{array}$ & $\begin{array}{l}\text { Tumor } \\
\text { visualized } \\
\text { by EUS, } \\
n(\%)\end{array}$ & $\begin{array}{l}\text { Adequate tissue } \\
\text { sample by } \\
\text { EUS-FNA, } \\
n(\%)\end{array}$ & $\begin{array}{l}\text { Correct } \\
\text { diagnosis by } \\
\text { EUS-FNA, } \\
n\end{array}$ & $\begin{array}{l}\text { Correct diagnosis } \\
\text { of any malignancy } \\
\text { by EUS-FNA, } n\end{array}$ & $\begin{array}{l}\text { Yield for correct } \\
\text { diagnosis }{ }^{\mathrm{b}} \\
(95 \% \mathrm{CI})\end{array}$ & $\begin{array}{l}\text { Sensitivity for } \\
\text { malignancyc } \\
(95 \% \mathrm{CI})\end{array}$ \\
\hline Varadarajulu [19], 2004 & Retrospective & 18 & $18(100)$ & $18(100)$ & $18(100)$ & 18 & 18 & $1.00(0.69-1.00)$ & $1.00(0.69-1.00)$ \\
\hline Annema [20], 2005 & Prospective & 32 & $32(100)$ & $32(100)$ & $31(97)$ & 31 & 31 & $0.97(0.81-1.00)$ & $0.97(0.81-1.00)$ \\
\hline Paquin [21], 2005 & Retrospective & 15 & $13(87)$ & $15(100)$ & $15(100)$ & 14 & 12 & $0.93(0.65-0.99)$ & $0.92(0.61-0.99)$ \\
\hline Sawhney [22], 2006 & Prospective & 19 & $18(95)$ & $16(84)$ & $16(84)$ & 13 & 12 & $0.68(0.45-0.85)$ & $0.67(0.43-0.84)$ \\
\hline Hernandez [23], 2007 & Retrospective & 17 & $17(100)$ & $17(100)$ & $17(100)$ & 17 & 17 & $1.00(0.68-1.00)$ & $1.00(0.68-1.00)$ \\
\hline Nguyen [24], 2011 & Retrospective & 24 & NR & $24(100)$ & $24(100)$ & 23 & NR & $0.96(0.76-0.99)$ & - \\
\hline Songür [25], 2011 ${ }^{\mathrm{a}}$ & Prospective & 22 & $20(91)$ & $22(100)$ & $17(77)$ & 16 & 16 & $0.73(0.51-0.87)$ & $0.80(0.57-0.92)$ \\
\hline Assisi [26], 2013 ${ }^{\mathrm{a}}$ & Retrospective & 11 & $11(100)$ & $11(100)$ & $11(100)$ & 11 & 11 & $1.00(0.58-1.00)$ & $1.00(0.58-1.00)$ \\
\hline $\begin{array}{l}\text { Vazquez-Sequeiros [27], } \\
2013\end{array}$ & Retrospective & 73 & NR & $62(85)$ & $61(84)$ & 60 & NR & $0.82(0.72-0.89)$ & - \\
\hline Nasir [28], 2014 & Retrospective & 55 & $55(100)$ & $55(100)$ & $52(95)$ & 52 & 52 & $0.95(0.84-0.98)$ & $0.95(0.84-0.98)$ \\
\hline Steinfort [29], 2016 & Retrospective & 27 & $27(100)$ & $27(100)$ & $27(100)$ & 26 & 26 & $0.96(0.78-0.99)$ & $0.96(0.78-0.99)$ \\
\hline
\end{tabular}

NR, not reported; EUS-FNA, endoscopic ultrasound-guided fine-needle aspiration.

a Unclear whether EUS had been able to visualize the tumor in all patients included, or whether the patients in whom this was not possible were excluded from the analysis.

b Yield was calculated as the number of patients in whom EUS-FNA made a correct biopsy-proven diagnosis (nonmalignant or malignant) divided by the total number of patients in whom EUS was performed with the aim of diagnosing an intrapulmonary tumor.

${ }^{c}$ Sensitivity was calculated as the number of patients in whom EUS-FNA made a correct biopsy-proven diagnosis of a malignancy divided by the total number of patients in whom the targeted intrapulmonary tumor turned out to be malignant.

from the analysis in whom intrapulmonary tumors could not be visualized by EUS. Four studies used a suboptimal reference standard in at least some of the patients, and 2 studies excluded patients due to missing reference standard results.

\section{Diagnostic Yield and Sensitivity}

Estimates of yield and sensitivity for the individual studies are reported in Table 3. The total number of patients with intrapulmonary tumors included in this review was 313; the number ranged from 11 to 73 across individual studies. The great majority of patients turned out to have a malignancy, with proportions ranging from 87 to $100 \%$ (median 100\%). The final diagnoses of intrapulmonary tumors are provided in Table 4.

The yield of EUS-FNA for diagnosing intrapulmonary tumors ranged from 0.68 to 1.00 across the included studies. The average yield after meta-analysis was 0.90 (95\% CI $0.82-0.95 ; I^{2}=55 \%$ ) (Fig. 3 ).

The sensitivity of EUS-FNA for diagnosing malignant intrapulmonary tumors ranged from 0.67 to 1.00 across the included studies, but it could not be calculated for 2 studies, as these did not report the total number of patients that had a malignant tumor. The average sensitivity after meta-analysis was $0.92\left(95 \%\right.$ CI $\left.0.83-0.96 ; I^{2}=53 \%\right)$ (Fig. 4).
Sources of Methodological and Clinical Heterogeneity

In the 7 studies that were considered to have a high risk of bias because they were retrospective, the average yield for diagnosing intrapulmonary tumors was 0.93 (95\% CI $0.86-0.96 ; I^{2}=32 \%$ ) (Fig. 3 ), and the average sensitivity for diagnosing malignant intrapulmonary tumors was 0.95 (95\% CI $0.90-0.98 ; I^{2}=0 \%$ ) (Fig. 4). As expected, this was lower - though the difference was not statistically significant - for the 3 prospective studies, for which these averages were $0.80\left(95 \%\right.$ CI $\left.0.56-0.93 ; I^{2}=65 \% ; p=0.11\right)$ and 0.83 (95\% CI 0.58-0.95; $I^{2}=66 \% ; p=0.06$ ), respectively.

Six studies were considered to have a high risk of bias because it was unclear whether EUS had been able to visualize the tumor in all patients included, or whether the patients in whom this was not possible were excluded from the analysis (Table 3 ). In these studies, the average yield was $0.93\left(95 \% \mathrm{CI} 0.80-0.98 ; I^{2}=47 \%\right)$, and the average sensitivity was 0.91 (95\% CI $\left.0.82-0.96 ; I^{2}=9 \%\right)$. The other 5 studies explicitly reported in how many of the patients EUS was unable to visualize the tumor, which varied from 16 to $0 \%$ (Table 3). In these studies, the average yield and average sensitivity were comparable to those from studies for which this information was unclear, i.e., $0.89\left(95 \%\right.$ CI $\left.0.76-0.95 ; I^{2}=68 \% ; p=0.56\right)$ and $0.90(95 \%$ CI $0.61-0.98 ; I^{2}=81 \% ; p=0.87$ ), respectively. 
Table 4. Final diagnoses of intrapulmonary tumors

\begin{tabular}{|c|c|c|c|c|}
\hline $\begin{array}{l}\text { Study [Ref.], } \\
\text { year }\end{array}$ & $\begin{array}{l}\text { Total EUS } \\
\text { performed, } n\end{array}$ & Final diagnosis: any malignancy, $n$ & Final diagnosis: benign, $n$ & $\begin{array}{l}\text { Final diagnosis of missed or incorrect } \\
\text { diagnosis by EUS-FNA, } n\end{array}$ \\
\hline $\begin{array}{l}\text { Varadarajulu [19], } \\
2004\end{array}$ & 18 & $\begin{array}{l}18 \\
\operatorname{NSCLC}(n=15) \\
\operatorname{SCLC}(n=1) \\
\text { Lung metastasis }(n=2)\end{array}$ & 0 & 0 \\
\hline $\begin{array}{l}\text { Annema }[20] \\
2005\end{array}$ & 32 & $\begin{array}{l}32 \\
\text { Squamous cell carcinoma }(n=4) \\
\text { Adenocarcinoma }(n=7) \\
\text { Large-cell undifferentiated carcinoma }(n=15) \\
\text { SCLC }(n=4) \\
\text { Giant-cell carcinoma }(n=1) \\
\text { Non-Hodgkin lymphoma }(n=1)\end{array}$ & 0 & $\begin{array}{l}1 \\
\text { Non-Hodgkin lymphoma }(n=1)\end{array}$ \\
\hline Paquin [21], 2005 & 15 & $\begin{array}{l}13 \\
\text { NSCLC }(n=10) \\
\text { Squamous cell carcinoma }(n=1) \\
\text { Lung metastasis }(n=2)\end{array}$ & $\begin{array}{l}2 \\
\text { No details reported }(n=2)\end{array}$ & $\begin{array}{l}1 \\
\text { Squamous cell carcinoma }(n=1)\end{array}$ \\
\hline $\begin{array}{l}\text { Sawhney [22], } \\
2006\end{array}$ & 19 & $\begin{array}{l}18 \\
\text { No details reported }(n=18)\end{array}$ & $\begin{array}{l}1 \\
\text { Pneumonia }(n=1)\end{array}$ & $\begin{array}{l}6 \\
\text { No details reported }(n=6)\end{array}$ \\
\hline $\begin{array}{l}\text { Hernandez [23], } \\
2007\end{array}$ & 17 & $\begin{array}{l}17 \\
\operatorname{NSCLC}(n=12) \\
\operatorname{SCLC}(n=4) \\
\text { Carcinoid }(n=1)\end{array}$ & 0 & 0 \\
\hline Nguyen [24], 2011 & 24 & NR & NR & NR \\
\hline Songür [25], 2011 & 22 & $\begin{array}{l}20 \\
\text { NSCLC }(n=14) \\
\text { SCLC }(n=3) \\
\text { Multiple myeloma }(n=1) \\
\text { Lung metastasis }(n=2)\end{array}$ & $\begin{array}{l}2 \\
\text { Schwannoma }(n=1) \\
\text { No details reported }(n=1)\end{array}$ & $\begin{array}{l}6 \\
\text { NSCLC }(n=1) \\
\text { Multiple myeloma }(n=1) \\
\text { Adenocarcinoma metastasis }(n=2) \\
\text { Schwannoma }(n=1) \\
\text { No details reported }(n=1)\end{array}$ \\
\hline Assisi [26], 2013 & 11 & $\begin{array}{l}11 \\
\text { Squamous cell carcinoma }(n=4) \\
\text { Adenocarcinoma }(n=5) \\
\text { Undifferentiated carcinoma }(n=2)\end{array}$ & 0 & 0 \\
\hline $\begin{array}{l}\text { Vazquez- } \\
\text { Sequeiros [27], } \\
2013\end{array}$ & $\begin{array}{l}73 \text { (final } \\
\text { diagnosis } \\
\text { available } \\
\text { for } 62 \text { ) }\end{array}$ & $\begin{array}{l}61 \\
\operatorname{NSCLC}(n=47) \\
\operatorname{SCLC}(n=8) \\
\text { Lung metastasis }(n=6)\end{array}$ & $\begin{array}{l}1 \\
\text { Hamartoma }(n=1)\end{array}$ & $\begin{array}{l}2 \\
\operatorname{NSCLC}(n=2)\end{array}$ \\
\hline Nasir [28], 2014 & 55 & $\begin{array}{l}55 \\
\operatorname{NSCLC}(n=47) \\
\operatorname{SCLC}(n=4) \\
\text { Lung metastasis }(n=4)\end{array}$ & 0 & $\begin{array}{l}3 \\
\operatorname{NSCLC}(n=3)\end{array}$ \\
\hline $\begin{array}{l}\text { Steinfort [29], } \\
2016\end{array}$ & 27 & $\begin{array}{l}27 \\
\text { NSCLC }(n=3) \\
\text { Squamous cell carcinoma }(n=4) \\
\text { Adenocarcinoma }(n=12) \\
\text { SCLC }(n=1) \\
\text { Undifferentiated carcinoma }(n=1) \\
\text { Lung metastasis }(n=5) \\
\text { Marginal zone B-cell lymphoma }(n=1)\end{array}$ & 0 & $\begin{array}{l}1 \\
\text { Marginal zone B-cell lymphoma }(n=1)\end{array}$ \\
\hline
\end{tabular}

NSCLC, non-small cell lung carcinoma; SCLC, small cell lung carcinoma; NR, not reported. 


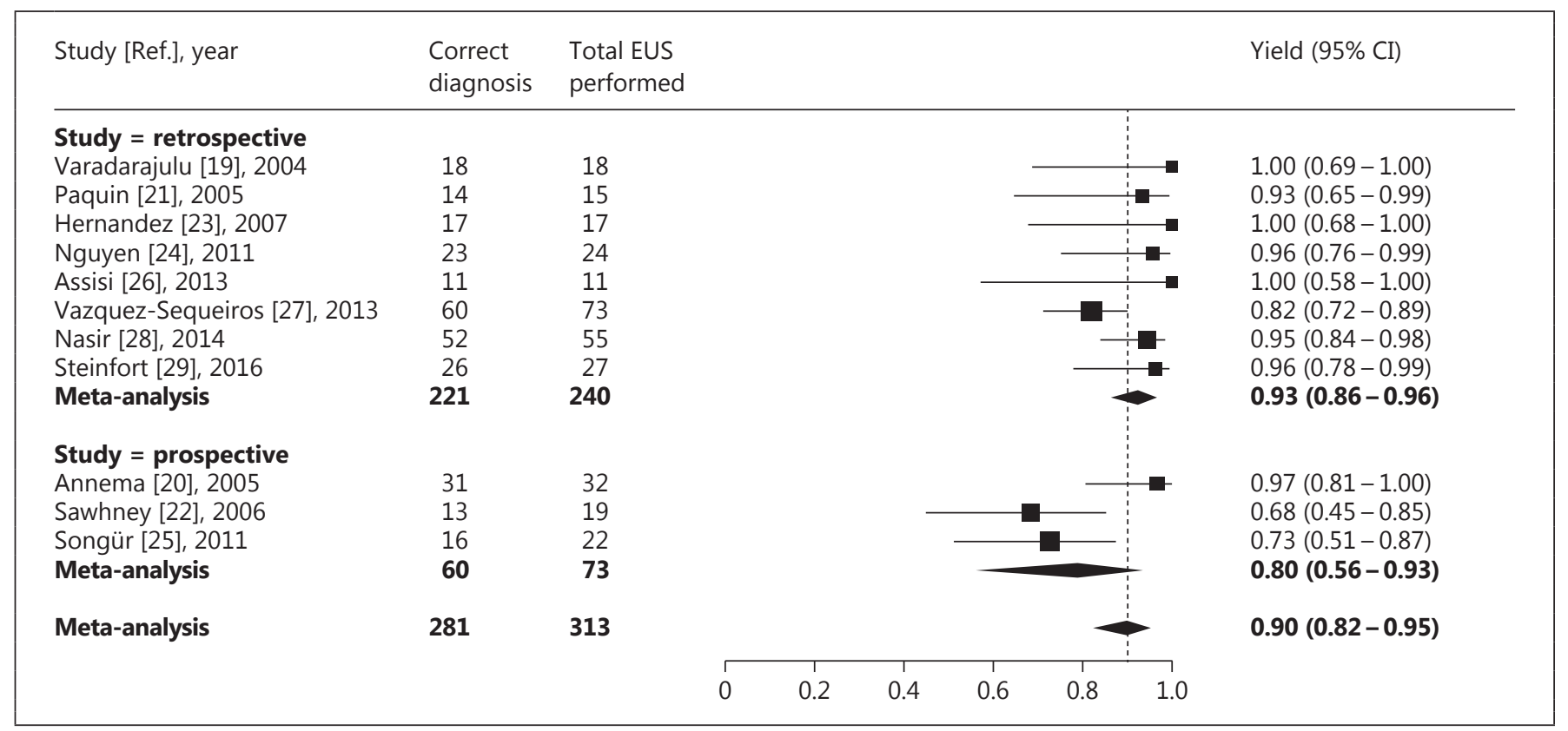

Fig. 3. Yield of EUS-FNA for diagnosing intrapulmonary tumors located near or adjacent to the esophagus. The difference in yield between retrospective and prospective studies was not statistically significant $(p=0.11)$.

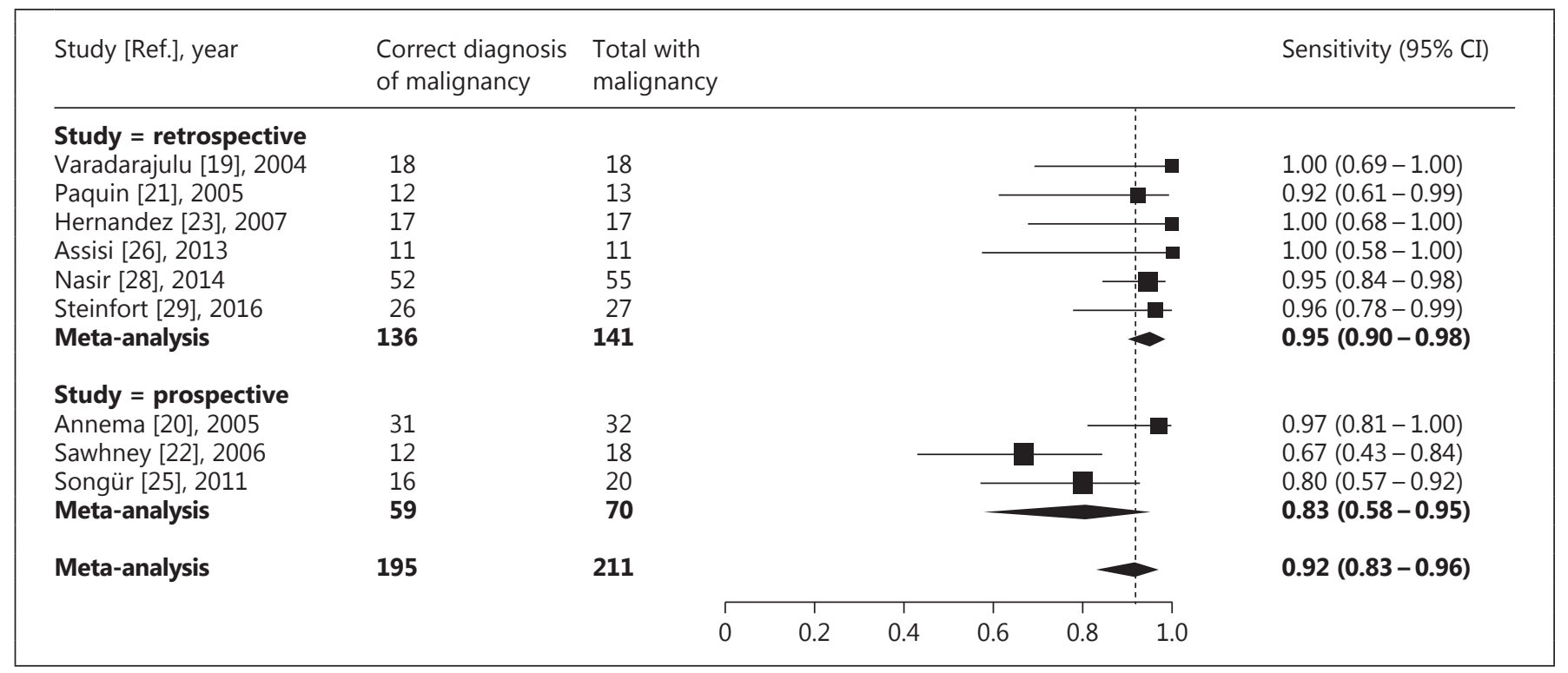

Fig. 4. Sensitivity of EUS-FNA for diagnosing malignant intrapulmonary tumors located near or adjacent to the esophagus. The difference in sensitivity between retrospective and prospective studies was not statistically significant $(p=0.06)$. 
The limited number of studies with a low risk of bias and with scarce reporting prohibited us from taking the anticipated clinical sources of heterogeneity into account in the subgroup analyses.

\section{Complications}

Three studies did not report whether there were any EUS-FNA-induced complications. Among the 8 studies that did report this information, complications occurred in 5 of 256 patients (2.0\%): 1 patient had self-limited severe chest pain that required admission, but no cause was identified; 1 patient had self-limited hemoptysis; 1 patient had hemoptysis with aspiration pneumonia; and 2 patients had a pneumothorax (Table 1). Mediastinitis, severe bleeding without hemoptysis, or perforation of the esophagus were not reported, neither were technical complications with damage to the equipment.

\section{Discussion}

The feasibility of EUS-FNA for obtaining an adequate tissue sample from intrapulmonary tumors located near or adjacent to the esophagus was first investigated in the early 2000s [19]. It is surprising that the number of subsequent evaluations on this topic is still low and mostly consists of retrospective studies with small sample sizes. The average yield of EUS-FNA for diagnosing intrapulmonary tumors in this meta-analysis was 0.90 , with a sensitivity for diagnosing malignant tumors of 0.92 , implying that EUS-FNA may be highly feasible for this purpose. However, several considerations need to be taken into account.

Almost all of the included studies had a high risk of bias. Most of these studies retrospectively included patients that had undergone EUS-FNA for diagnosing an intrapulmonary tumor at their institution. Such nonconsecutive inclusion is likely to lead to a highly selected sample of patients, perhaps with tumors that are relatively large and easy to reach by EUS-FNA. This will irrevocably lead to estimates of test performance that cannot be reproduced in practice if applied to any patient with an intrapulmonary tumor located near or adjacent to the esophagus. We considered this to be the major potential source of bias in our review. Not surprisingly, the average yield was 0.13 higher in the retrospective studies than in the prospective studies, although the confidence intervals were wide and the difference was not statistically significant.
Only 5 of the studies included explicitly reported on the number of patients in whom the tumor could not be visualized by EUS. For the remaining studies, it seems that they might have only included patients in their final analysis if the authors were able to actually visualize the tumor - or perhaps even only if they were able to take an adequate tissue sample from it with EUS-FNA. This practice would inflate estimates of yield and sensitivity. Again, we took this into account by performing subgroup analyses, but in this case, we found no major differences in yield.

The proportion of patients with malignancy across the included studies was unusually high, with a median of $100 \%$. We can only speculate about the reason for this, but it may, again, be related to the retrospective nature of most studies. The prevalence of malignant tumors is likely to be lower in practice.

None of the included studies reported on the proportion of patients that were considered eligible to undergo EUS-FNA for diagnosing an intrapulmonary tumor relative to the total number of patients presenting with an intrapulmonary tumor that required a tissue diagnosis during the recruitment period; the latter group also included tumors located more peripherally. This is a factor that influences the potential usefulness of EUS-FNA in this setting, because a low proportion would imply that this indication rarely occurs.

The statistical heterogeneity was substantial in our meta-analysis. Elements such as the experience of the endoscopist, the tumor size, and the location of the tumor with respect to the esophagus are likely to have a major influence on yield [30,31]. Due to the limited number of eligible studies and scarce reporting, we were unable to take these elements into account. It is expected that most studies were performed by highly experienced endoscopists, and that estimates of yield may not be immediately applicable to endoscopists with less experience. Most of the studies included were not specific about how close the tumors were located to the esophagus. All of this together may explain the large variety in yield.

A substantial number of studies have evaluated the performance of EUS-FNA in diagnosing mediastinal tumors and in mediastinal nodal staging in patients with lung cancer [11], and this application is now recommended in most clinical guidelines [12-14]. However, the number of evaluations on the performance of EUS-FNA in diagnosing intrapulmonary tumors is clearly lagging behind [10]. Based on our own experience, we believe EUS-FNA should be considered for those patients who present with an intrapulmonary tumor located adjacent 
or near the esophagus, especially in cases where the alternative is surgery. This hypothesis is further supported by the findings of this review. However, also in cases in which EUS-FNA is used to establish a biopsy-based diagnosis, bronchoscopy remains the standard for obtaining a complete overview of the endobronchial situation, especially if patients are potentially eligible for surgical removal of the intrapulmonary tumor.

The general awareness among physicians that the esophagus can be a valuable route for the diagnosis and staging of lung cancer is still limited [9, 32]. EUS-FNA is a safe procedure; complications only occurred in $2.0 \%$ of patients, and they were mostly mild. Since only 2 of 229 patients had a pneumothorax due to EUS-FNA, routine performance of chest radiography after EUS-FNA of intrapulmonary tumors may not be indicated. EUS-FNA is also relatively inexpensive and provides the advantage that it can combine diagnosis and $\mathrm{T}$-, $\mathrm{N}$-, and M-staging with biopsies in a single procedure.

EUS-FNA can be performed in an outpatient setting under local anesthesia. Using EUS-FNA, left and lower paraesophageal structures can be reached [8]. As such, it is complementary to EBUS-TBNA, which provides access to structures close to the large airways on both sides [9]. The advantages of EUS-FNA over EBUS-TBNA are that it is better tolerated by patients, that the transducer is in close contact with the target due to endoscopic suction on the esophagus, and that tissue sampling is not hampered by cartilage rings.

Recent studies have also investigated the yield of linear EBUS-TBNA for diagnosing centrally located intrapulmonary tumors in case the lung mass is located adjacent to the major airways $[33,34]$. A combined approach with EUS-FNA and EBUS-TBNA for mediastinal lymph node staging is implemented more and more in clinical practice [9]. Such an approach could also be useful in the diagnosis of centrally located intrapulmonary tumors, as has recently been demonstrated [35]. Especially the fact that increasing numbers of endoscopists perform both EBUS and EUS in a single session with an EBUS-scope (EUS-B) could facilitate the biopsy-proven diagnosis of intrapulmonary tumors and could lead to a highly efficient, cheap, minimally invasive procedure with a limited patient burden. However, only in 1 of the included studies EUS-B was performed using an EBUS-scope; the yield and sensitivity in this study were in the same range as in studies that used an endoscope [29]. Further research will need to confirm whether EUS-B indeed produces equal results for diagnosing intrapulmonary tumors. The advantages of using an EUS-scope over an EBUS-scope are that its ultrasonic window angle is larger, that the ultrasonic picture is of higher quality, that small structures are more easily visualized, and that the maneuverability of the needle is better.

Larger prospective studies should be performed to evaluate whether our findings are reproducible. Such studies could assess the impact of tumor size and tumor location with regard to the esophagus on the performance of EUS-FNA.

In conclusion, the findings of our review suggest that EUS-FNA is safe and has a high yield and sensitivity for diagnosing intrapulmonary tumors, but these findings are limited by the small number of high-quality studies. Future prospective studies are recommended to evaluate whether these findings are reproducible and to further refine the criteria for recommending EUS-FNA in this setting.

\section{Financial Disclosure and Conflicts of Interest}

This research did not receive any specific grant from funding agencies in the public, commercial, or not-for-profit sectors. The authors have no conflicts of interest to declare.

\section{References}

1 Torre LA, Bray F, Siegel RL, Ferlay J, LortetTieulent J, Jemal A: Global cancer statistics, 2012. CA Cancer J Clin 2015;65:87-108.

2 Rivera MP, Mehta AC, Wahidi MM: Establishing the diagnosis of lung cancer: Diagnosis and Management of Lung Cancer, 3rd ed: American College of Chest Physicians evidence-based clinical practice guidelines. Chest 2013;143(suppl):e142S-e165S.

3 Nakajima T, Yasufuku K, Fujiwara T, Chiyo M, Sekine Y, Shibuya K, Hiroshima K, Yo- shino I: Endobronchial ultrasound-guided transbronchial needle aspiration for the diagnosis of intrapulmonary lesions. J Thorac Oncol 2008;3:985-988.

4 Oki M, Saka H, Kitagawa C, Kogure Y, Murata N, Adachi T, Ando M: Rapid on-site cytologic evaluation during endobronchial ultrasound-guided transbronchial needle aspiration for diagnosing lung cancer: a randomized study. Respiration 2013;85:486492 
5 Gilbert C, Akulian J, Ortiz R, Lee H, Yarmus L: Novel bronchoscopic strategies for the diagnosis of peripheral lung lesions: present techniques and future directions. Respirology 2014;19:636-644.

6 Steinfort DP, Khor YH, Manser RL, Irving LB: Radial probe endobronchial ultrasound for the diagnosis of peripheral lung cancer: systematic review and meta-analysis. Eur Respir J 2011;37:902-910.

7 Boskovic T, Stanic J, Pena-Karan S, Zarogoulidis P, Drevelegas K, Katsikogiannis N, Machairiotis N, Mpakas A, Tsakiridis K, Kesisis G, Tsiouda T, Kougioumtzi I, Arikas S, Zarogoulidis K: Pneumothorax after transthoracic needle biopsy of lung lesions under CT guidance. J Thorac Dis 2014;6(suppl 1):S99S107.

8 Colella S, Vilmann P, Konge L, Clementsen PF: Endoscopic ultrasound in the diagnosis and staging of lung cancer. Endosc Ultrasound 2014;3:205-212.

9 Vilmann P, Clementsen PF: Combined EUS and EBUS are complementary methods in lung cancer staging: do not forget the esophagus. Endosc Int Open 2015;3:E300-E301.

10 Vilmann P, Clementsen PF, Colella S, Siemsen M, De Leyn P, Dumonceau JM, Herth FJ, Larghi A, Vasquez-Sequeiros E, Hassan C, Crombag L, Korevaar DA, Konge L, Annema JT: Combined endobronchial and esophageal endosonography for the diagnosis and staging of lung cancer: European Society of Gastrointestinal Endoscopy (ESGE) Guideline, in cooperation with the European Respiratory Society (ERS) and the European Society of Thoracic Surgeons (ESTS). Endoscopy 2015; 47:545-559.

11 Micames CG, McCrory DC, Pavey DA, Jowell PS, Gress FG: Endoscopic ultrasound-guided fine-needle aspiration for non-small cell lung cancer staging: a systematic review and metaanalysis. Chest 2007;131:539-548.

12 De Leyn P, Dooms C, Kuzdzal J, Lardinois D, Passlick B, Rami-Porta R, Turna A, Van Schil P, Venuta F, Waller D, Weder W, Zielinski M: Revised ESTS guidelines for preoperative mediastinal lymph node staging for non-smallcell lung cancer. Eur J Cardiothorac Surg 2014;45:787-798

13 Silvestri GA, Gonzalez AV, Jantz MA, Margolis ML, Gould MK, Tanoue LT, Harris LJ, Detterbeck FC: Methods for staging non-small cell lung cancer: Diagnosis and Management of Lung Cancer, 3rd ed: American College of Chest Physicians evidence-based clinical practice guidelines. Chest 2013;143(suppl): e211S-e250S.
14 Detterbeck FC, Jantz MA, Wallace M, Vansteenkiste J, Silvestri GA; American College of Chest Physicians: Invasive mediastinal staging of lung cancer: ACCP evidence-based clinical practice guidelines (2nd edition). Chest 2007(suppl);132:202S-220S

15 Yasuda I, Kato T, Asano F, Okubo K, Omar S, Kako N, Yasuda S, Sano K, Soehendra N, Moriwaki H: Mediastinal lymph node staging in potentially resectable non-small cell lung cancer: a prospective comparison of CT and EUS/EUS-FNA. Respiration 2009;78:423431.

16 Whiting PF, Rutjes AW, Westwood ME, Mallett S, Deeks JJ, Reitsma JB, Leeflang MM, Sterne JA, Bossuyt PM; QUADAS-2 Group: QUADAS-2: a revised tool for the quality assessment of diagnostic accuracy studies. Ann Intern Med 2011;155:529-536.

17 DerSimonian R, Laird N: Meta-analysis in clinical trials. Control Clin Trials 1986;7:177188.

18 Higgins JP, Thompson SG: Quantifying heterogeneity in a meta-analysis. Stat Med 2002; 21:1539-1558.

19 Varadarajulu S, Hoffman BJ, Hawes RH, Eloubeidi MA: EUS-guided FNA of lung masses adjacent to or abutting the esophagus after unrevealing CT-guided biopsy or bronchoscopy. Gastrointest Endosc 2004;60:293297.

20 Annema JT, Veseliç M, Rabe KF: EUS-guided FNA of centrally located lung tumours following a non-diagnostic bronchoscopy. Lung Cancer 2005;48:357-361; discussion 363364.

21 Paquin SC, Hoffman BJ, Hawes RH, Chong AK, Faias SR, Hoda RS: Utility of on-site cytologic assessment of transesophageal endoscopic ultrasound-guided fine needle aspiration of lung masses (abstract). Gastrointest Endosc 2005;61:AB296.

22 Sawhney MS, Kratzke RA, Lederle FA, Holmstrom AM, Nelson DB, Kelly RF: EUS-guided FNA for the diagnosis of advanced lung cancer. Gastrointest Endosc 2006;63:959-965.

23 Hernandez A, Kahaleh M, Olazagasti J, Jones DR, Daniel T, Stelow E, White GE, Shami VM: EUS-FNA as the initial diagnostic modality in centrally located primary lung cancers. J Clin Gastroenterol 2007;41:657-660.

24 Nguyen TQ, Kalade A, Prasad S, Desmond P, Wright G, Hart D, Conron M, Chen RY: Endoscopic ultrasound guided fine needle aspiration (EUS-FNA) of mediastinal lesions. ANZ J Surg 2011;81:75-78.
25 Songür N, Songür Y, Bircan S, Kapucuoğlu N: Comparison of 19- and 22-gauge needles in EUS-guided fine needle aspiration in patients with mediastinal masses and lymph nodes. Turk J Gastroenterol 2011;22:472-478.

26 Assisi D, Filippetti M, Federici T, Visca P, Anti M: Role of EUS FNA in diagnosis and staging of lung cancer. Dig Liver Dis 2013; 45:S76-S77.

27 Vazquez-Sequeiros E, Levy MJ, Van Domselaar M, González-Panizo F, Foruny-Olcina JR, Boixeda-Miquel D, Juzgado-Lucas D, Albillos A: Diagnostic yield and safety of endoscopic ultrasound guided fine needle aspiration of central mediastinal lung masses. Diagn Ther Endosc 2013;2013:150492.

28 Nasir BS, Edwards M, Tiffault V, Kazakov J, Khereba M, Ferraro P, Liberman M: Transesophageal pulmonary nodule biopsy using endoscopic ultrasonography. J Thorac Cardiovasc Surg 2014;148:850-855; discussion 855.

29 Steinfort DP, Farmer MW, Irving LB, Jennings BR: Pulmonologist-performed per-oesophageal needle aspiration of parenchymal lung lesions using an EBUS bronchoscope: diagnostic utility and safety. J Bronchology Interv Pulmonol 2016, in press.

30 Konge L, Colella S, Vilmann P, Clementsen PF: How to learn and to perform endoscopic ultrasound and endobronchial ultrasound for lung cancer staging: a structured guide and review. Endosc Ultrasound 2015;4:4-9.

31 Konge L, Annema J, Vilmann P, Clementsen $\mathrm{P}$, Ringsted C: Transesophageal ultrasonography for lung cancer staging: learning curves of pulmonologists. J Thorac Oncol 2013;8: 1402-1408.

32 Annema JT: When will we finally adopt endoscopic ultrasound? Chest 2014;146:e117.

33 Verma A, Jeon K, Koh WJ, Suh GY, Chung MP, Kim H, Kwon OJ, Um SW: Endobronchial ultrasound-guided transbronchial needle aspiration for the diagnosis of central lung parenchymal lesions. Yonsei Med J 2013;54: 672-678.

34 Tournoy KG, Rintoul RC, van Meerbeeck JP, Carroll NR, Praet M, Buttery RC, van Kralingen KW, Rabe KF, Annema JT: EBUS-TBNA for the diagnosis of central parenchymal lung lesions not visible at routine bronchoscopy. Lung Cancer 2009;63:45-49.

35 Bugalho A, Ferreira D, Eberhardt R, Dias SS, Videira PA, Herth FJ, Carreiro L: Diagnostic value of endobronchial and endoscopic ultrasound-guided fine needle aspiration for accessible lung cancer lesions after non-diagnostic conventional techniques: a prospective study. BMC Cancer 2013;13:130.
Esophageal Endosonography for Intrapulmonary Tumors
Respiration 2017;93:126-137 DOI: $10.1159 / 000452958$ 